\title{
DÜBLIN
}

Technological University Dublin

ARROW@TU Dublin

\section{Antidiabetic Activities of an LC/MS Fingerprinted Aqueous Extract of Fagonia cretica L. in Preclinical Models}

Imran Nazir

The Islamia University of Bahawalpur, Pakistan

Nisar ur Rahman

COMSATS Institute of Information Technology, Pakistan

Zunaira Alvi

The Islamia University of Bahawalpur, Pakistan

See next page for additional authors

Follow this and additional works at: https://arrow.tudublin.ie/schfsehart

Part of the Life Sciences Commons, and the Medicine and Health Sciences Commons

\section{Recommended Citation}

Nazir, I., Rahman, N., Alvi, Z., Rahman, H., Sendker, J., Zhang, T., Frankish, N. and Sheridan, H. (2017). Antidiabetic activities of an LC/MS Fingerprinted aqueous extract of Fagonia cretica L. in preclinical models. Planta Medica, 83, 1141-1148.

This Article is brought to you for free and open access by the School of Food Science and Environmental Health at ARROW@TU Dublin. It has been accepted for inclusion in Articles by an authorized administrator of ARROW@TU Dublin. For more information, please contact arrow.admin@tudublin.ie, aisling.coyne@tudublin.ie, gerard.connolly@tudublin.ie.

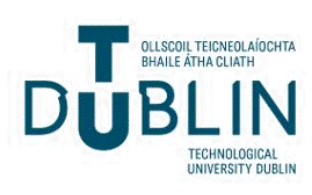




\section{Authors}

Imran Nazir, Nisar ur Rahman, Zunaira Alvi, M. Hafizur Rahman, Jandirk Jandirk Sendker, Tao Zhang, Neil Frankish, and Helen Sheridan 


\title{
Anti-diabetic activities of an LC/MS Fingerprinted Aqueous Extract of Fagonia Cretica L. in Preclinical Models.
}

Imran Nazir ${ }^{1,5}$, Nisar ur Rahman ${ }^{2}$, Zunaira Alvi ${ }^{1}$, M. Hafizur Rahman ${ }^{3}$, Jandirk Sendker ${ }^{4}$, Tao Zhang $^{5}$, Neil Frankish ${ }^{5}$, Helen Sheridan ${ }^{5}$

\begin{abstract}
Affiliations
${ }^{1}$ Department of Pharmacy, The Islamia University of Bahawalpur, Bahawalpur, Pakistan

${ }^{2}$ Department of Pharmacy, COMSATS Institute of Information Technology, Abbottabad Campus, Islamabad, Pakistan

${ }^{3}$ Dr. Panjwani Center for Molecular Medicine and Drug Research, International Center for Chemical and Biological Sciences, University of Karachi, Karachi, Pakistan

${ }^{4}$ University of Münster, Institute of Pharmaceutical Biology and Phytochemistry, Münster, Germany

${ }^{5}$ Trinity College Dublin, School of Pharmacy \& Pharmaceutical Sciences and Trinity Biosciences Institute (TBSI), Dublin, Ireland
\end{abstract}

\section{Corresponding author}

Dr. Helen Sheridan

Trinity College Dublin

School of Pharmacy and Pharmaceutical Sciences \& Trinity Biosciences Institute

Dublin 2

Ireland

Email: hsheridn@tcd.ie

Phone: +35318962828

Fax: +35318962810 
Keywords: Traditional Medicine, Fagonia Cretica L., Zygophyllaceae, flavonoid glycosides, anti-diabetic, Streptozotocin-Nicotinamide, $\alpha$-Glucosidase inhibitor.

\section{Abbreviations}

Alanine aminotransferase

Alpha glucosidase inhibitors

Aspartate aminotransferase

Diabetes mellitus

Dipeptidyl peptidase-4

ALT

1,1-Diphenyl-2-picryl-hydrazyl

AGIs

Glucagon-like peptide-1

Middle East and North Africa:

$p$-nitro phenyl $\alpha$-D-glucopyranoside

Traditional Medicine

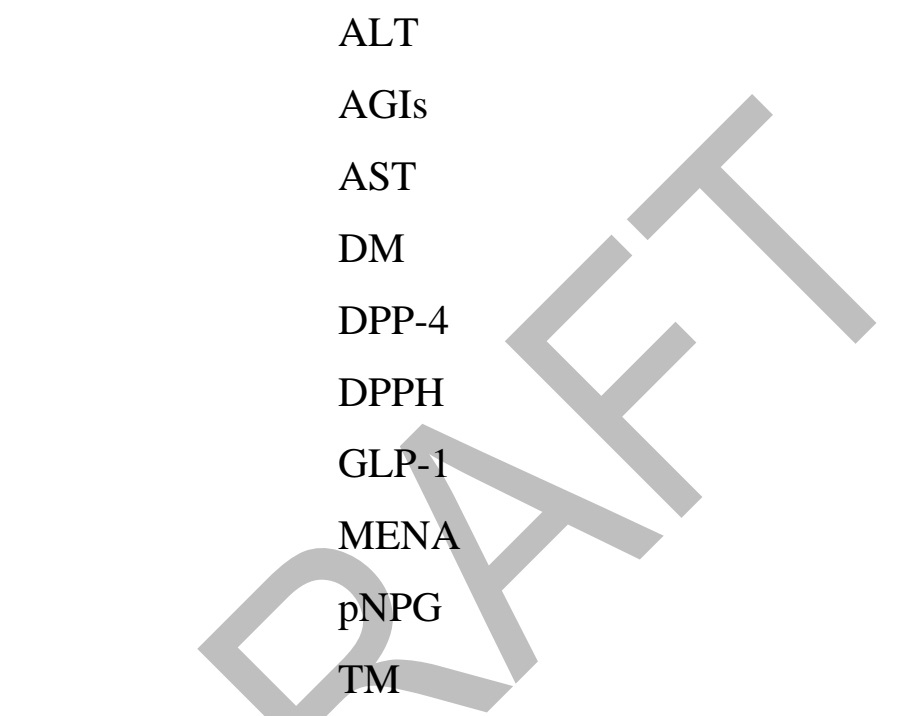

*Dedicated to Professor Dr. Max Wichtl in recognition of his outstanding contribution to pharmacognosy research. 


\begin{abstract}
Diabetes mellitus is a chronic disease and one of the most important public health challenges facing mankind. Fagonia cretica L. (Zygophyllaceae) is a medicinal plant used widely in the Punjab in Pakistan. A recent survey has demonstrated that traditional healers and herbalists frequently use this plant to treat diabetes. In the current study, the traditional medicine was prepared as a tea and the profile of the main metabolites present in the traditional medicine was analysed via LC/MS/MS. The extract was shown to contain a number of phenolic glycosides including quercetin-3-O-rutinoside, kaempferol-3-O-rutinoside, kaempferol-3-O-glycoside, kaempferol-3(6'-malonylglucoside), isorhamnetin-3-O-rutinoside, and isorhamnetin-3-(6' malonylglucoside) in addition to unidentified sulphonated saponins. The traditional medicine inhibits $\alpha$-glucosidase in vitro with an $\mathrm{IC}_{50}$ of $4.62 \mu \mathrm{g} / \mathrm{ml}$. The hypoglycaemic effect of the traditional medicine was evaluated in normoglycaemic and streptozotocin-treated diabetic rats, using glibenclamide as internal control. The preparation ( 250 or $500 \mathrm{mg} / \mathrm{kg}$ body weight) was administered once a day for 21 consecutive days. The dose of $500 \mathrm{mg} / \mathrm{kg}$ was effective in the management of the disease, causing a $45 \%$ decrease in plasma glucose level at the end of the experimental period. Histological analysis of pancreatic sections confirmed that streptozotocin/nictotinamide treatment caused destruction of pancreatic islet cells, while pancreatic sections from treatment groups showed that both the extract and glibenclamide partially prevented this deterioration. The mechanism of this protective effect is not clear. However, such a finding suggests that ingestion of the tea could confer additional benefits and should be investigated further.
\end{abstract}




\section{Introduction}

DM is a metabolic disorder caused by either an absolute or relative lack of insulin activity and is characterised by an increased level of blood glucose leading to thirst and diuresis [1]. Further, it is associated with long term micro vascular and macro vascular complications, such as diabetic retinopathy, neuropathy, nephropathy and many others [2]. The rate of occurrence of DM is escalating and has more than doubled globally since the early 1990's with a 35.4 million people suffering from the disease in the MENA region of which Pakistan contributes 7.02 million diabetics [3]. The predicted increase in numbers of sufferers is 51.4\% in Pakistan compared with a regional increase of $39.2 \%$ over a single generation gap. This imposed a financial burden of USD. 17.1 billion spent on the management of diabetes in the region during 2015 [4]. Lifestyle changes for the management of type $2 \mathrm{DM}$ include diet and exercise while groups including the AACE, the Dutch College of General Practitioners and the IDF advocate AGI's as first line therapy for its treatment [5,6,7]. AGIs act by inhibition of alpha glucosidase enzymes and fermentation of colonic starch and specifically target the postprandial hyperglycaemia [8, 9]. New classes of anti-diabetic drugs such as DPP-4 inhibitors, GLP-1 analogues and combined receptor type 1 antagonists have been introduced in recent years. Studies have shown that the combined administration of AGIs and DPP-4 inhibitors result in significant decrease in plasma glucose fluctuations and are effective in reducing post prandial glycaemic excursions [10, 11]. Other therapies for diabetes include the drugs that act as secretagogues or sensitisers of beta cells or by the inhibition of gluconeogenesis [12].

Over $70 \%$ of the population in countries like Pakistan still depend on TM options (Unani, Ayurvedic) for their primary care [13], particularly in rural areas. This is due to a number of factors such as inadequate or limited access to the modern medical systems and affordability. In addition Unani, Ayurveda, and homeopathy have been accepted and integrated into the national health system in Pakistan and are widely used throughout the country. There are approximately 52,600 registered Unani medical practitioners that serve the nation through both the public and private sectors in urban and rural areas $[13,14]$. An extensive survey among traditional healers and herbalists in in the city of Bahawalpur and the Cholistan Desert in Pakistan was carried out comprising of 99 informants during 2011 and 2012. This study collected data relating to the use of medicinal flora for the treatment of diabetes [15]. The traditional healers and herbalists in this study claimed to diagnose DM in their patients by observing symptoms such as weight loss, 
fatigue, excessive urination and the presence of sugar in the urine. Fagonia Cretica L. (family Zygophyllaceae) was frequently mentioned and highly recommended by both the traditional healers and rural dwellers.

The genus Fagonia is composed of circa 35 different species, which are distributed across tropical, subtropical and arid areas of the world and on all continents except Australia [16]. Several Fagonia species feature in Asian TM systems including Ayurveda and Unani [17, 18]. F. cretica L. is found in North Africa, Spain, Cyprus, Turkey, and Saudi Arabia and throughout the desert regions of western India and Pakistan [16]. A wide range of therapeutic uses have been recently reviewed for F. cretica L., including anti-tumor, anti-inflammatory and neuroprotective have recently been reviewed [17]. There only reports for the traditional use of F. cretica L. in the treatment of diabetes cite its use as part of a multi-herbal mixture, where it is used in equal quantities with aerial parts of Aloe vera and F. Tylophorahirsuta L. combined as an aqueous extract $[19,20]$.

Crude phytochemical extracts and isolated compounds from F. cretica $L$. have been shown to have a diverse range of biological activities including amongst others anti-haemorrhagic, antitumor, anti-inflammatory and neuroprotective cytotoxic anti-inflammatory and neuroprotective $[21,22,23,24]$. Active metabolites including the anti-inflammatory and anti-tumour triterpenes taraxerol and ursolic acid [25, 26], and triterpenoid saponins with hederagenin and ursolic acid and oleanoic acid aglycones have been isolated and the general presence of flavonoids has been demonstrated [27, 28, 29]. In 2012, Lam et al. [30] demonstrated that an aqueous extract of $F$. cretica L. induces DNA damage, cell arrest and apoptosis in MCF-7 (WT-p53) and MDA-MB231 (mutant $-\mathrm{p} 53$ ) breast cancer cells. However, despite the interesting results presented in this study, there is no chemical fingerprint or characterisation of the extract investigated. More recently Saleem et al. [31] isolated quinovic acid, quinovic acid-3 $\beta$-O- $\beta$-d-glycopyranoside,

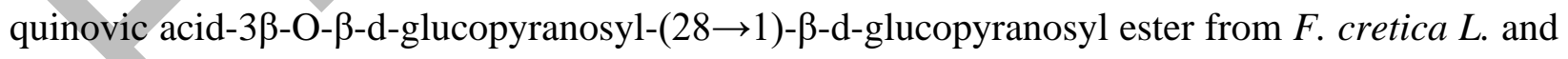
have identified them as potential as potential DPP-4 inhibitors which might have use in the treatment of diabetes and may explain in part the reported use of the TM in the treatment of DM.

Despite the body of phytochemical information that exists around F. cretica $L$. and the well acknowledged differences in metabolomic composition of herbal materials that can be caused by cultivation, environment and other factors $[32,33]$ no study to date using this TM has 
reported on the metabolomics profile. In this study, the chemical fingerprint for the TM of $F$. cretica $L$. has been generated by $L C / M S / M S$, and this profile directly corresponds to the TM which shows positive effects in in vivo and in vitro models of diabetes.

\section{Materials and Methods}

\section{Chemicals}

Streptozotocin (purity $\geq 95 \%$ by HPLC) was purchased from Calibiochem $®$ (EMD Chemicals, San Diego, CA, USA), Nicotinamide (purity $\geq 99 \%$ by HPLC) was purchased from Acer Scientific (USA) and Glibenclamide (purity $\geq 99 \%$ by HPLC) and D-glucose from Sigma (St. Louis, MO, USA). HbA1c, creatinine, urea, ALT and AST test kits were purchased from Merck (Pakistan). All other chemicals and reagents used were of analytical grade.

\section{Plant Materials}

The fresh aerial parts of the Fagonia Cretica L. (Zygophyllaceae) were collected after monsoon during the month of May in 2012 from an area of abundant plant growth named Laatan Shinghar in the Cholistan Desert, district Bahawalpur, Punjab, Pakistan. The taxonomic identification of the plant was carried out by Prof. Dr. Muhammad Arshad Choudhary (Late), Director, Cholistan Institute of Desert Studies (CIDS), Islamia University of Bahawalpur (IUB) and Pakistan. The voucher specimens (3401/CIDS/IUB) for the plant were prepared and deposited at the herbarium of CIDS, IUB.

\section{Preparation of the Extract}

Fresh plant material $(2.0 \mathrm{Kg})$ was washed with tap water to remove the dust and other foreign particles and dried under shade. The dried plant material was chopped into small pieces $(1 \times 1 \mathrm{~cm}$ approx.) and extracted with boiling water ( 2 L) overnight as practiced by the local informants. The aqueous extract was cooled and lyophilized. The percent yield of the lyophilized powder was $10.15 \%$ of the dry plant material. 


\section{LC-MS/MS analysis}

Chromatographic separations were performed on a Dionex Ultimate 3000 RS liquid chromatography system on a Dionex Acclaim RSLC 120 C18 column $(2.1 \times 100 \mathrm{~mm}, 2.2 \mu \mathrm{m})$ with a binary gradient (A: water with $0.1 \%$ formic acid; $\mathrm{B}$ : acetonitrile with $0.1 \%$ formic acid) at $0.8 \mathrm{~mL} / \mathrm{min}$ : 0 to $9.5 \mathrm{~min}$, linear from $5 \% \mathrm{~B}$ to $100 \% \mathrm{~B} ; 9.5$ to $12.5 \mathrm{~min}$, isocratic $100 \% \mathrm{~B} ; 12.5$ to $12.6 \mathrm{~min}$, linear from $100 \% \mathrm{~B}$ to $5 \% \mathrm{~B} ; 12.6$ to $15 \mathrm{~min}$, isocratic $5 \% \mathrm{~B}$. The injection volume was $2 \mu \mathrm{L}$.

Samples were analysed by as described in Sendker et al. [34] with the following modifications: MS frequency was increased to $4 \mathrm{~Hz}$; AutoMS2-mode was activated to target each Full-scan-mass-spectrum's three most abundant ions of $\mathrm{m} / \mathrm{z}$ 200-1000 and minimum intensity of 2000 counts for up to two MS/MS experiments with the following setting: 624 summations with $80 \mathrm{eV}$ collision energy and $130 \mathrm{Vpp}$ collision RF + 313 summations with 16 $\mathrm{eV}$ and $130 \mathrm{Vpp}+313$ summations with $16 \mathrm{eV}$ and $300 \mathrm{Vpp}$ were merged to one MS/MS spectrum. An ion that had been chosen twice as precursor ion was excluded from further MS/MS experiments for one typical chromatographic peak-base-width of 0.1 min. Full-scan MS- and MS/MS spectra were typically extracted from the mass-calibrated raw data by using the Dissect Compounds function of Compass Data Analysis 4.1 SR1. Spectra of the three most abundant residual chromatographic peaks (compounds 8-10) were extracted by integrating the corresponding time-ranges from a base peak chromatogram (mass range $\mathrm{m} / \mathrm{z}$ 200-1000). Product ions were obtained from MS/MS experiments of protonated molecules or ammonium adduct ions, or from the Full-scan mass-spectra if no suitable MS/MS experiment was triggered. UV spectra were extracted by integrating the corresponding peaks from UV chromatograms at $\lambda=$ $230 \mathrm{~nm}$ or $\lambda=280 \mathrm{~nm}$. All UV spectra and the Full-scan mass spectra of compounds 8-10 were corrected by subtracting from them the respective data of the respective peak borders. All other Full-scan mass spectra were corrected during the Dissect-Compounds-Processing by excluding any mass signal with deviating elution profile. Molecular formulas were determined using the Smart Formula tool of Data Analysis 4.1 SR1 under consideration of UV spectra and unambiguously determined ion formulas of smaller product ions. 


\section{Animals}

Ethical approval for the animal studies was obtained from the Animal Use Committee of the International Centre for Chemical and Biological Sciences (ICCBS), University of Karachi, Pakistan. In-house bred healthy adult female Wistar rats weighing 180-220 g (ICCBS) were utilised throughout the experiment. Animals were housed in standard environmental conditions of temperature, humidity, and light: dark cycle in clean polypropylene cages lined with husk bed and were fed on standard rodent diet with free access to water throughout the period of study.

\section{In Vitro Studies Enzyme Inhibition Studies: $\alpha$ - Glucosidase inhibition assay}

To determine the enzyme inhibition activity of the compound, the enzyme ( $\alpha$-glucosidase) from yeast (Saccharomyces cerevisiae) and the substrate (pNPG) was purchased from Sigma Aldrich, USA. The standard enzyme inhibition protocol used in the Enzyme Inhibition Laboratory of the Department of Pharmacy, COMSATS Institute of Information Technology, Abbottabad, Pakistan, was adopted with some modifications [35]. The assay was performed using 96-well plates. Solutions of the inhibitor (in methanol) and that of the enzyme and the substrate (in 0.07 $\mathrm{M}$ phosphate buffer, $\mathrm{pH}$ 6.8) were prepared using the standard procedures described for the assay. The enzyme $\left(2.5 \mathrm{UmL}^{-1}\right)$ and the test compound $(10 \mu \mathrm{L}$ each $)$ were pre-incubated at $37^{\circ} \mathrm{C}$ for $30 \mathrm{~min}$ before the addition of the substrate $(10 \mu \mathrm{L})$ to each well of 96 -well plate. The reaction mixture was incubated at $37^{\circ} \mathrm{C}$ for $30 \mathrm{~min}$ and stopped by adding $80 \mu \mathrm{L}$ of $0.2 \mathrm{M} \mathrm{Na} \mathrm{CO}_{3}$. Acarbose and methanol were used as positive and negative control, respectively. The inhibitory activity of the compound was determined by measuring the p-nitro phenol released from pNPG at $405 \mathrm{~nm}$ using spectrophotometer (BioTek ELx800). The \% inhibition was calculated by following equation:

$$
\% \text { Inhibition }=\frac{(\text { Absorbance of Control }- \text { Absorbance of Sample })}{\text { Absorbance of Control }} \times 100
$$

$\mathrm{IC}_{50}$ value (Concentration of the inhibitor that inhibited $50 \%$ of $\alpha$-glucosidase activity) was calculated using non-linear curve fitting program GraphPad PRISM 5.0 (San Diego, California, USA). 


\section{In Vivo animal Studies - Acute Oral Toxicity Evaluation}

The $F$. cretica L. extract was evaluated for acute oral toxicity in rats. A single oral administration of the extract at different doses (500 and $1000 \mathrm{mg} / \mathrm{kg}$ body weight), was given to two different groups consisting of five Wistar rats. The animals were observed for behavioural and toxic (mortality) effects continuously at short intervals of time, initially for $24 \mathrm{~h}$, and then again at 48 and $72 \mathrm{~h}$, following extract administration. Serum biochemical parameters were also evaluated to check the toxicity to kidney and liver.

\section{Evaluation of Extract in Normal Healthy Rats}

Serum glucose levels of the animals were checked (after an overnight fasting period of 12-14 h,) by collecting the blood by snipping the tail vein using a glucometer Accu-Chek® (Roche Diagnostics, Mannheim, Germany). The animals were then divided into two groups ( $\mathrm{n}=$ $5 /$ group). Group 1 served as the control, while group 2 was given a single oral dose of $500 \mathrm{mg} / \mathrm{kg}$ of the extract. Serum glucose levels of the animals were checked at $0,1,2$, and $3 \mathrm{~h}$. The values are expressed as mean \pm SEM and $p$-value was calculated.

\section{Induction of Diabetes}

Rats were fasted for 12-14 $\mathrm{h}$ before the induction of the experimental diabetes. Non-insulin dependent diabetes mellitus (NIDDM) (Type II) was induced in rats by a single iv. injection of $60 \mathrm{mg} / \mathrm{kg}$ of Streptozotocin, freshly prepared in cold citrate buffer $(0.1 \mathrm{M}, \mathrm{pH} 4.5)$ followed after $15 \mathrm{~min}$ by $120 \mathrm{mg} / \mathrm{kg}$ of freshly dissolved Nicotinamide in normal saline, injected intraperitoneally. Control rats were injected with an equivalent volume of citrate buffer only. Rats were given the glucose solution $(5 \%)$ for $24 \mathrm{~h}$. Diabetes was confirmed by the elevated levels of serum glucose after $72 \mathrm{~h}$ and then on day 7 by collecting fasting blood by snipping the tail vein, and serum glucose was determined by glucose oxidase-peroxidase (GOD-POD) method. Only those rats that have fasting blood glucose above $250 \mathrm{mg} / \mathrm{dl}$ were selected and used for the study.

\section{Study Design and Evaluation of TM in Experimental Animals}

Once the diabetes was confirmed the animals were divided randomly into five groups consisting of five animals each $(n=5)$ as follows: 
Group I: Non-diabetic control rats

Group II: Untreated diabetic control rats

Group III: Diabetic rats treated with $F$. cretica $250 \mathrm{mg} / \mathrm{kg}$ of body weight

Group IV: Diabetic rats treated with $F$. cretica $500 \mathrm{mg} / \mathrm{kg}$ of body weight

Group V: Diabetic rats treated with glibenclamide

Group III and IV were given their respective treatments after one week of induction of diabetes. The first day of treatment was considered as Day 0. The treatment was continued till day 21. Freshly prepared solutions of extracts in distilled water $(5 \mathrm{~mL})$ were fed orally to the rats at a dose of $250 \mathrm{mg} / \mathrm{kg}$ and $500 \mathrm{mg} / \mathrm{kg}$ body weight, once a day for 21 days to group III and IV, respectively. Group I and II were given water only in place of extract, while group V was treated with the standard drug Glibenclamide $(5 \mathrm{mg} / \mathrm{kg})$.

Body weights and serum sugar levels were determined weekly after an overnight fasting of 12-14 h. On day 22, the animals were anaesthetised after an overnight fasting using sodium pentothal $(60 \mathrm{mg} / \mathrm{kg})$, sacrificed, and their blood and organs were collected for further biochemical and histopathological examinations, respectively.

\section{Histopathological Studies}

Organs (Pancreases and Kidneys) were removed after dissection and placed in neutral buffered formalin $(\mathrm{NBF}, 10 \%)$ for fixation. Then, they were washed repeatedly with distilled water, dehydrated with increasing concentrations of 2- propanol, and embedded in paraffin. Sections (5 $\mu \mathrm{m}$ thick) were made using microtome blades. The sections were deparaffinised, rehydrated with decreasing concentrations of 2-propanol, and mounted on glass slides. The slides were stained with haematoxylin and eosin, double blinded, and analysed.

\section{Statistical Analysis}

Data are expressed as the mean \pm SEM. Statistical analyses were performed by using the Statistical Package for Social Science version 15.0 (SPSS) and GraphPad PRISM 5.0. Analysis of Variance (ANOVA) followed by unpaired and paired $t$-tests (2-tailed) were performed to detect any significant differences of means between and within group. Differences were considered as statistically significant for $p$-values less than or equal to $0.05(p \leq 0.05)$. 


\section{Results and Discussion}

The TM sample was prepared as a tea using freshly dried aerial parts as described by traditional healers [15]. The powder was lyophilised and was analysed using a modification of the methods described by Sendker et al. [34]. The corresponding LC/MS chromatographic fingerprint shows the main components of the extract (Fig. S1, Supporting Information). High-resolution MS and MS/MS spectra of these peaks were obtained from a representative LC-MS data set that was analysed using the Dissect Compounds algorithm of Data Analysis 4.0 (Bruker Daltonics). The algorithm detected 26 compounds. Expansions (Fig. 1), are focused on relevant peaks. The main peaks were tentatively characterised and correspond to glycosides of quercetin, kaempferol and isorhamnetin (Table 1 and Table S1, Supporting Information). The major compounds and their fragmentation patterns are shown in Fig. 2. Such glycosides have previously been detected in other Fagonia species [16, 29]. An unidentified iridoid-like compound (Fig. 1; peak 9; Fig. S2, Supporting Information) together with two sulphonated triterpenoid saponins (Fig. 1; peaks 17 and 18; Fig. S3, Supporting Information) have been detected, and although not fully characterised, they are reported in this TM for the first time. Sulphonated saponins of the ursolic acid aglycone have been isolated from related species $F$, indica [35].

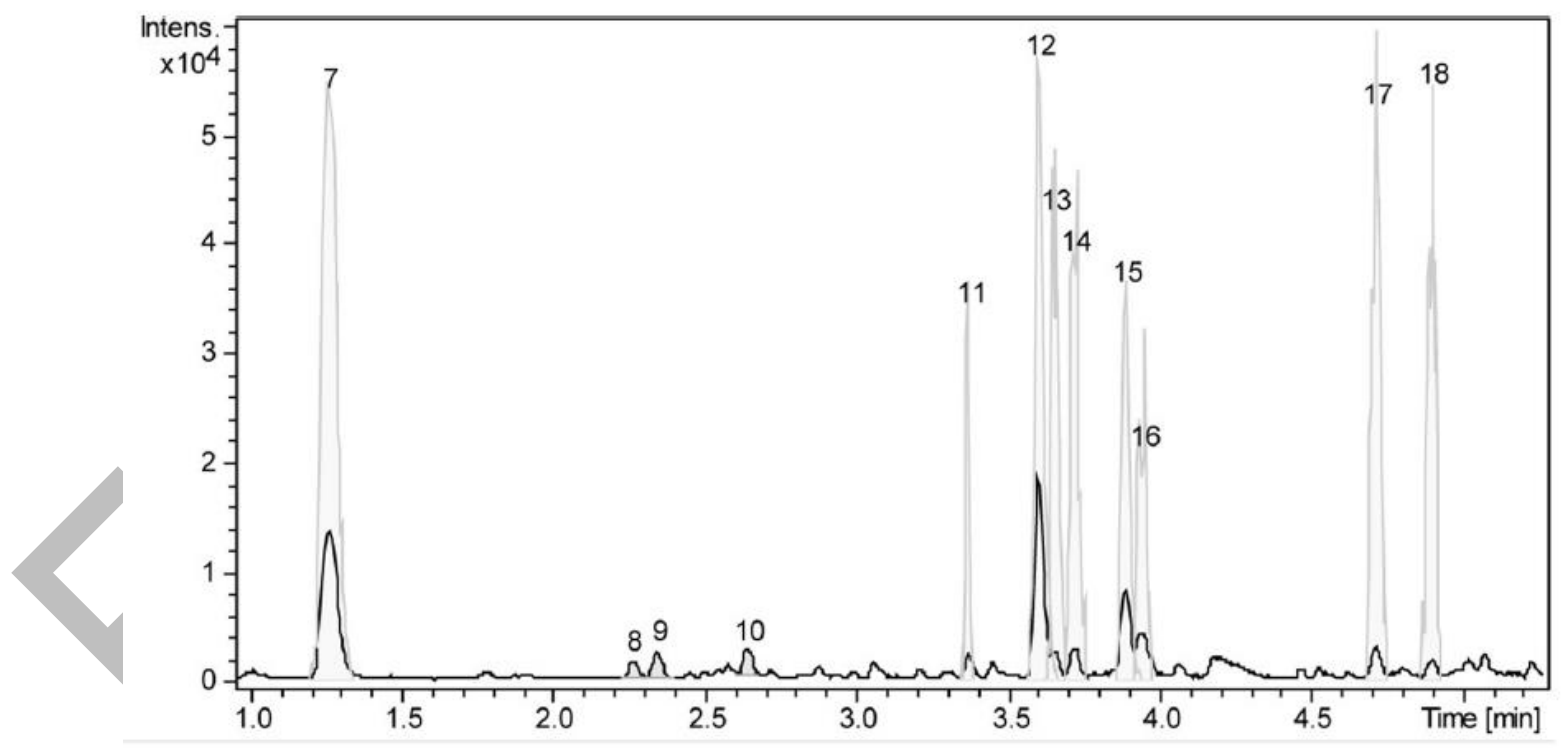

Fig. 1. LC/MS profile of $F$. cretica TM focused on relevant peaks., The dark line represents a base peak chromatogram of $\mathrm{m} / \mathrm{z}$ 200-1000. Peaks 8, 9, and 10 have been detected from the BPCplot, the others by using the Dissect-Compounds-Algorithm of Bruker Data Analysis 4.1. 
Table 1. The M/z's for major compounds in the TM tea of $F$. cretica $\mathrm{L}$ by LC/MS in the positive ionisation mode. NI=Not identified, NFI=Not fully identified.

\begin{tabular}{|c|c|c|c|c|c|c|}
\hline $\begin{array}{c}\mathbf{R}_{\mathrm{t}} \\
(\mathbf{m i n})\end{array}$ & Peak No & $\mathbf{m} / \mathbf{z}$ & Adduct ion(s) & $\begin{array}{l}\text { MS/MS Fragment ions (m/z) } \\
\text { (rel. Int. in percent) }\end{array}$ & $\begin{array}{l}\text { Molecular } \\
\text { formula }\end{array}$ & Identity \\
\hline 1.278 & 7 & 257.0652 & {$[\mathrm{M}+\mathrm{H}]^{+}$} & $\begin{array}{c}\text { MS1: } 211.0600(14), 193.0481 \\
(10), 147.0429(12), 119.0487 \\
(7), 107.0489(8)\end{array}$ & $\mathrm{C}_{11} \mathrm{H}_{13} \mathrm{O}_{6}$ & Piscidic acid \\
\hline 2.354 & 9 & 389.1078 & {$[\mathrm{M}+\mathrm{H}]^{+}$} & $\begin{array}{c}\text { MS1: } 371.0966(17), 297.0534 \\
\text { (8), 265.1421 (20), } 213.0763 \\
{\left[\text { base peak] }{ }^{+}\right.}\end{array}$ & $\mathrm{C}_{16} \mathrm{H}_{21} \mathrm{O}_{10}$ & $\begin{array}{l}\text { Glycoside*. The } \\
\text { aglycone is } \mathrm{C}_{10} \mathrm{H}_{13} \mathrm{O}_{5}, \\
\mathrm{~m} / \mathrm{z} 213 \text { Possible } \\
\text { iridoid glycoside. }\end{array}$ \\
\hline 3.371 & 11 & 611.1587 & {$[\mathrm{M}+\mathrm{H}]^{+}$} & MS1: 303.0561 (17) & $\mathrm{C}_{27} \mathrm{H}_{31} \mathrm{O}_{16}$ & $\begin{array}{l}\text { Quercetin-3-O- } \\
\text { rutinoside (Rutin) }\end{array}$ \\
\hline 3.603 & 12 & 595.1654 & {$[\mathrm{M}+\mathrm{H}]^{+}$} & $\begin{array}{c}\text { MS2: } 595.1642(54), 449.1091 \\
(41), 287.0567(100)\end{array}$ & $\mathrm{C}_{27} \mathrm{H}_{31} \mathrm{O}_{15}$ & $\begin{array}{l}\text { Keampferol-3-O- } \\
\text { rutinoside }\end{array}$ \\
\hline 3.656 & 13 & 625.1787 & {$[\mathrm{M}+\mathrm{H}]^{+}$} & $\begin{array}{c}\text { MS2: } 625.1828(62), 479.1186 \\
(32), 317.0683(100) \\
285.0358(13)\end{array}$ & $\mathrm{C}_{28} \mathrm{H}_{33} \mathrm{O}_{16}$ & $\begin{array}{l}\text { Isorhamnetin-3-O- } \\
\text { rutinoside }\end{array}$ \\
\hline 3.722 & 14 & 449.1100 & & MS2: $449.1201(37), 287.0574$ & $\mathrm{C}_{21} \mathrm{H}_{21} \mathrm{O}_{11}$ & $\begin{array}{l}\text { Kaempferol-3- } \\
\text { glucoside }\end{array}$ \\
\hline 3.888 & 15 & 535.1096 & {$\left[\mathrm{M}+\mathrm{H}^{+}\right.$} & MS1: $287.0536(9)$ & $\mathrm{C}_{24} \mathrm{H}_{23} \mathrm{O}_{14}$ & $\begin{array}{l}\text { Kaempferol-3(6'- } \\
\text { malonylglucoside) }\end{array}$ \\
\hline 3.964 & 16 & 565.1 & {$[\mathrm{M}+\mathrm{H}]^{+}$} & MS1: 287.0506 (14) & $\mathrm{C}_{25} \mathrm{H}_{25} \mathrm{O}_{15}$ & $\begin{array}{l}\text { Isorhamnetin 3-(6"- } \\
\text { malonylglucoside }\end{array}$ \\
\hline 4.711 & 17 & & {$[\mathrm{M}+\mathrm{Na}]^{+}$} & $\begin{array}{c}\text { MS1: } 715.3730(100) \\
635.4144(14), 553.3210(59)\end{array}$ & $\mathrm{C}_{42} \mathrm{H}_{68} \mathrm{NaO}_{17} \mathrm{~S}$ & $\begin{array}{l}\text { NFI: Saponin } \\
\text { dihexoside of } \\
\mathrm{C}_{30} \mathrm{H}_{48} \mathrm{O}_{7} \mathrm{~S} \\
\end{array}$ \\
\hline 4.895 & 18 & 985.4082 & {$[\mathrm{M}+\mathrm{Na}]^{+}$} & $\begin{array}{l}\text { MS1: } 801.3719(100) \\
553.323215(26)\end{array}$ & $\mathrm{C}_{45} \mathrm{H}_{70} \mathrm{NaO}_{20} \mathrm{~S}$ & $\begin{array}{c}\text { NFI: Saponin } \\
\text { dihexoside, malonated }\end{array}$ \\
\hline
\end{tabular}




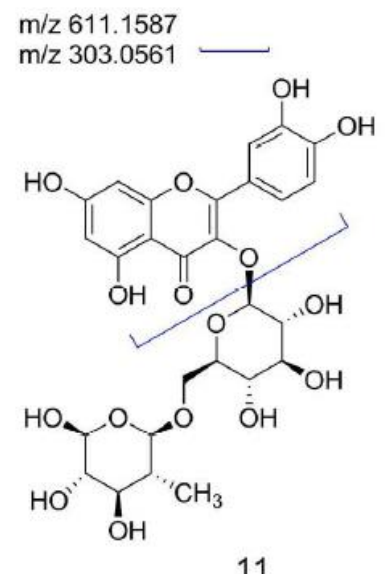

11

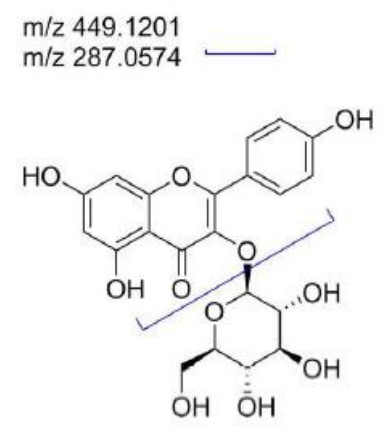

14
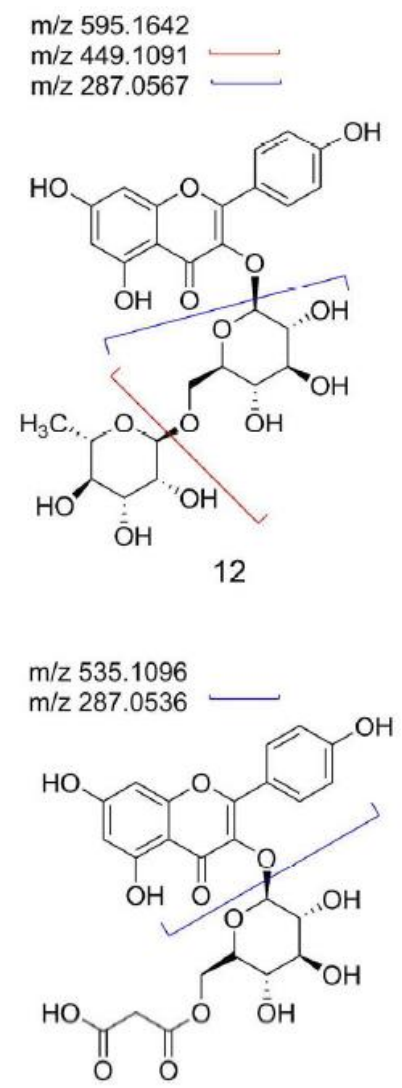

15

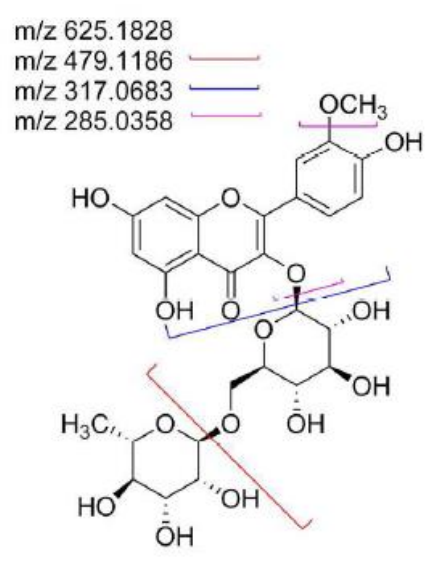

13

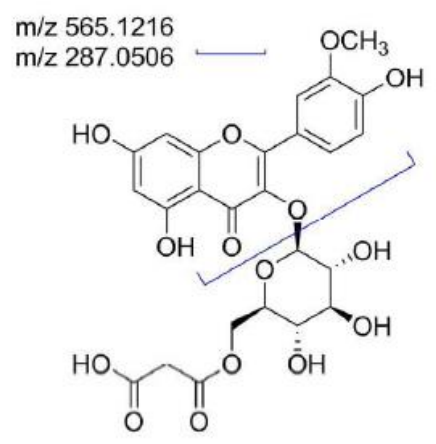

16

Fig. 2. Fragmentation patterns for the most abundant flavonoid glycosides characterised by LC/MS in the TM of $F$. cretica.

In an acute toxicity study, the TM of F. cretica did not show any abnormal behaviour, no mortality was recorded up to the dose of $1,000 \mathrm{mg} / \mathrm{kg}$ body weight. Body weights and food consumption were similar to that of the control group and no significant differences were seen. No makers of toxicity were seen, which indicates that there were no gross pathological changes or any toxic effect on chronic administration of the extract, reflecting a good safety profile at a preliminary level. Thus, it can be concluded that F. cretica L. extract was safe at a dose of 1000 $\mathrm{mg} / \mathrm{kg}$. The observed safety profile of the TM (Table S2, Supporting Information) is in keeping with its traditional use over long periods.

Free radicals can be damaging and lead to various chronic diseases such as diabetes, arthritis, and asthma [37]. Using the DPPH radical assay, the free radical scavenging activity of the F. cretica L. TM did not show any significant inhibition (33\%) compared to the standard control, Propyl gallate $(90.01 \%)$. However the radical scavenging potential of phytochemically 
derived ethyl acetate fraction of Fagonia Cretica L. is highly significant (93\%). This reinforces the differences that exist between crude fractions, isolates and the actual TM administered and reinforces the need for studies that concentrate on the actual formulation of the herbal drug that is administered as a medicine.

Competitive inhibition of the key hydrolysing enzymes of carbohydrate digestion ( $\alpha$ glucosidase and $\alpha$-amylase) present in the small intestine is an important approach for the management of diabetes [38] and is especially suited for a traditional Pakistani carbohydrate rich diet where carbohydrates contribute to over $60 \%$ of the usual Pakistani or South Asian diet [39]. The alpha glucosidase inhibitory effect of the TM was determined using $\alpha$-glucosidase from yeast (Saccharomyces cerevisiae) using the substrate pNPG and 96-well plates and standardised protocols [35]. The standard $\alpha$-glucosidase inhibitor acarbose was used as a control (Fig. 3). The $\mathrm{IC}_{50}$ value for $\alpha$ - glucosidase inhibition of $4.62 \mu \mathrm{g} / \mathrm{ml}$ (95\% confidence limits between 3.066 and $6.916 \mu \mathrm{g} / \mathrm{ml}$ ) was obtained for the $\mathrm{TM}$, while the $\mathrm{IC}_{50}$ value of acarbose was 17.4 $\mu \mathrm{g} / \mathrm{ml}$ (95\% confidence limits between 11.44 and $25.7 \mu \mathrm{g} / \mathrm{ml}$ ). Thus, inhibitory activity of the TM is comparable to that of the commercially available standard drug acarbose. Furthermore, common side effects of acarbose might include abdominal distention and pain and diarrhea, though such side effects are not associated with $F$. cretica as a TM [17].

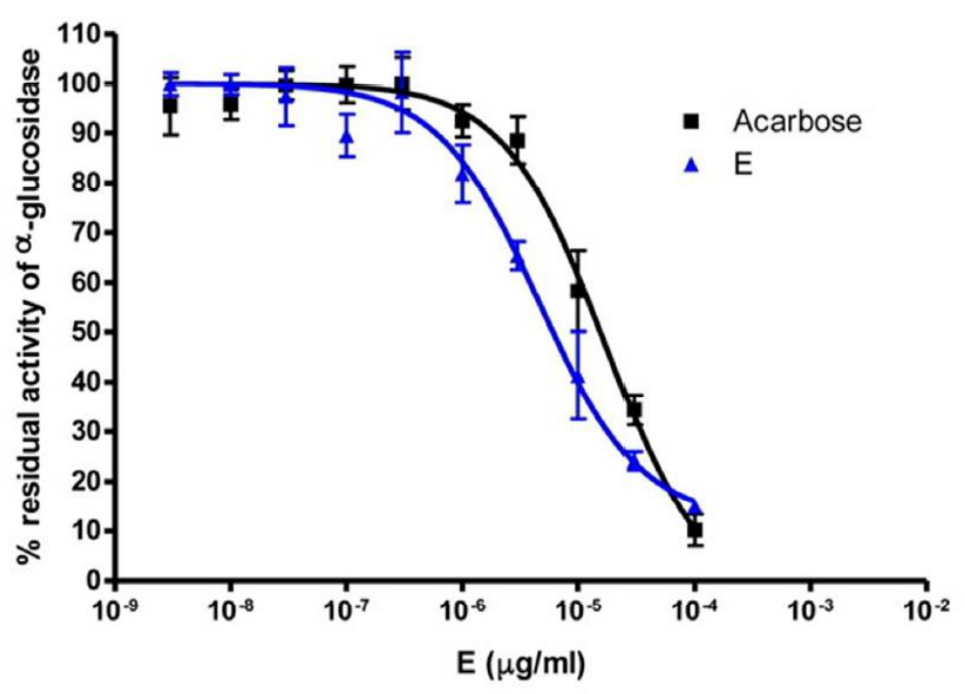

Fig. 3. Effect of $F$. cretica and acarbose on $\alpha$-glucosidase inhibitory activity assessed by spectrophotometric measurement at $405 \mathrm{~nm}$ of p-nitro phenol released from pNPG by $\alpha-$ glucosidase from $\mathrm{S}$. cerevisiae. Values are expressed as the mean $\pm \mathrm{SEM}, \mathrm{n}=3$. 
In this study a graded dose response on serum glucose levels was observed in normal healthy rats, when they were treated with the TM of $F$. cretica L. The dose-dependent hypoglycemic effects of the TM extract were observed in animals treated with $250 \mathrm{mg} / \mathrm{kg}$ and $500 \mathrm{mg} / \mathrm{kg}$ of body weight, causing a $4.6 \%(\mathrm{p}=0.01)$ and $15.97 \%(\mathrm{p}=0.003)$ decrease in serum glucose levels, respectively, after $3 \mathrm{~h}$ of treatment. Serum glucose levels were recorded for $3 \mathrm{~h}$ and the results showed a gradual decrease in the plasma glucose levels when compared with the normal untreated group (Fig. 4). Since F. cretica can reduce blood glucose levels in normolgycaemic animals, there exists the possibility that high doses might precipitate a hypoglycaemic crisis and potential coma. However, such an effect has not been reported as a consequence of its use in TM [17]. The effects of the TM on repeated administration on a daily basis in STZ-NIC-induced diabetic rats is shown in Fig. 5.

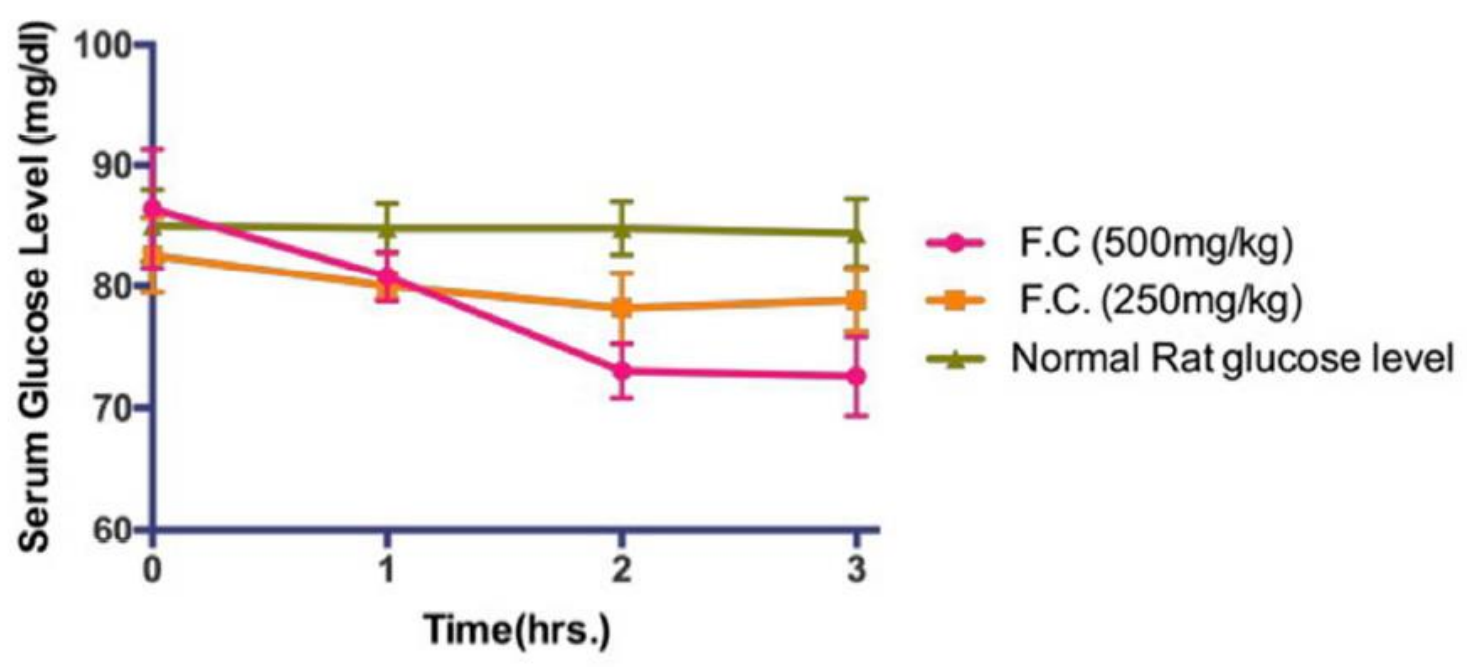

Fig. 4. Effects of $F$. cretica at 250 and $500 \mathrm{mg} / \mathrm{kg}$ on fasting blood glucose levels in female Wistar normoglycemic rats. Values are expressed as the mean \pm SEM, $n=5$. 


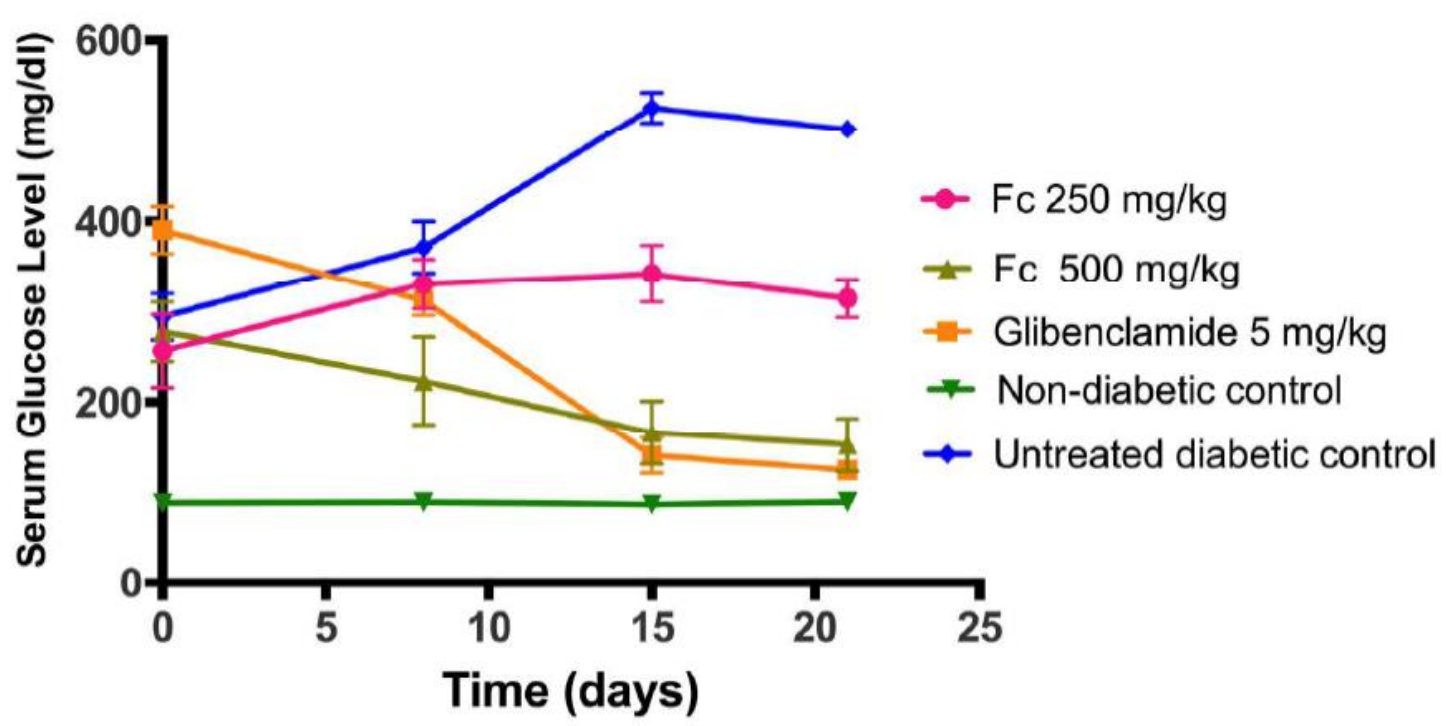

Fig. 5. Effects of F. cretica at 250 and $500 \mathrm{mg} / \mathrm{kg}$ and glibenclamide $5 \mathrm{mg} / \mathrm{kg}$ on STZ/NIC diabetic rats given $5 \%$ glucose solution for $24 \mathrm{~h}$. Values are expressed as the mean \pm SEM, $n=5$.

The blood glucose lowering effects of the plant extract were evaluated at two different doses $(250 \mathrm{mg} / \mathrm{kg}$ and $500 \mathrm{mg} / \mathrm{kg})$. The effect was found to be dose dependent. Both of the doses showed a fasting blood glucose lowering effect with a more pronounced and significant $(\mathrm{p}<$ 0.05 ) effects observed with $500 \mathrm{mg} / \mathrm{kg}$ (45\% decrease) at the end of the experimental period on day 21 when compared with that of the untreated diabetic group. The group treated with 250 $\mathrm{mg} / \mathrm{kg}$ did not show any significant decrease in serum sugar levels of the rats, while glibenclamide (GB) at a dose of $5 \mathrm{mg} / \mathrm{kg}$ treated group reduced the serum glucose levels by $56.4 \%$. Serum glucose levels of different treatment groups on day 0 and day 21 are compared in Table 2. It should be noted that the blood glucose-lowering effect of the extracts in streptozocininduced diabetic rats was not a consequence of the alpha-glucosidase inhibitory activity, since these rats were fed with $5 \%$ glucose solution. While the hypoglycaemic target in diabetic rats is currently unknown, it is separate and distinct from the alpha-glucosidase inhibitory activity, and both activities may be additive in the clinical setting. 
Table 2. Serum glucose levels of different treatment groups on day 0 and day 21. Effects of F. cretica at 250 and $500 \mathrm{mg} / \mathrm{kg}$ and glibenclamide $5 \mathrm{mg} / \mathrm{kg}$ on STZ/NIC diabetic rats given $5 \%$ glucose solution for $24 \mathrm{~h}$. Values are expressed as the mean $\pm \mathrm{SEM}, \mathrm{n}=5$. *** $\mathrm{p}<0.001$.

\begin{tabular}{|llll|}
\hline \multirow{2}{*}{ Sr. No. } & Treatment Groups & \multicolumn{2}{c|}{ Fasting Serum Glucose $\mathrm{mg} / \mathrm{dl}$} \\
\cline { 3 - 4 } & & Day 0 & Day 21 \\
\hline 1. & Normal Control $(\mathrm{n}=5)$ & $88.00 \pm 2.74$ & $89.20 \pm 1.20$ \\
2. & Untreated Diabetic $(\mathrm{n}=5)$ & $294.00 \pm 25.71$ & $501.60 \pm 9.10$ \\
3. & F.c. Treated $250 \mathrm{mg} / \mathrm{kg}(\mathrm{n}=5)$ & $246.00 \pm 36.88$ & $248.20 \pm 21.58$ \\
4. & F.c. treated $500 \mathrm{mg} / \mathrm{kg}(\mathrm{n}=5)$ & $277.40 \pm 32.80$ & $152.40 \pm 29.46^{* * *}$ \\
5. & GB Treated $(\mathrm{n}=5)$ & $281.00 \pm 6.979$ & $122.60 \pm 4.49^{* * *}$ \\
\hline
\end{tabular}

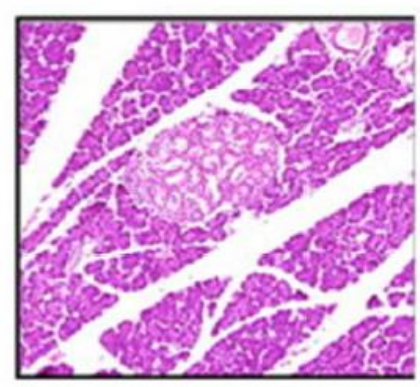

A. Pancreas of Normal Control

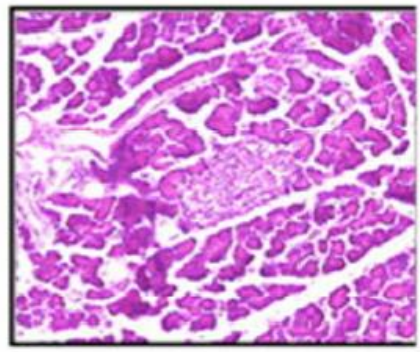

C. Pancreas of F.C. Treated $(500 \mathrm{mg} / \mathrm{kg})$

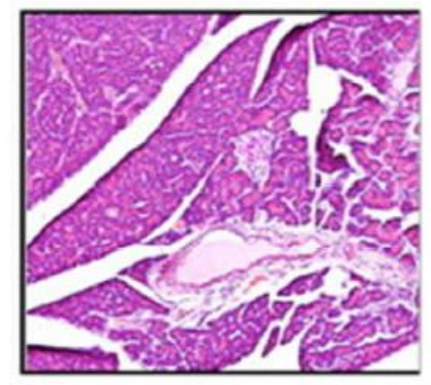

B. Pancreas of untreqated diabetic rat

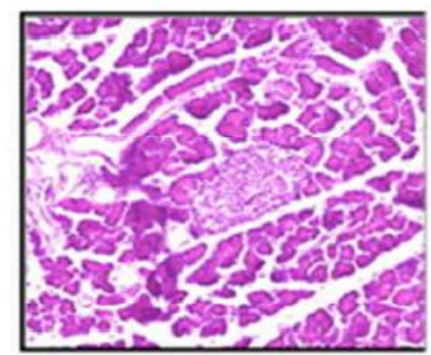

D. Pancreas of F.C. Treated $(250 \mathrm{mg} / \mathrm{kg})$

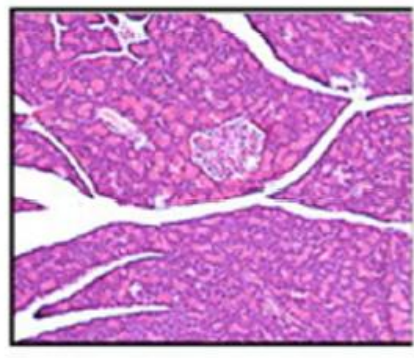

E. Pancreas of GB Treated

Fig. 6. Histology of Pancreas of different treatment groups: a. Pancreas of normal control. b. Pancreas of untreated diabetic. c. Pancreas of $F$. cretica treated $(500 \mathrm{mg} / \mathrm{kg})$. d. Pancreas of $F$. cretica treated $(250 \mathrm{mg} / \mathrm{kg})$. e. Pancreas of GB treated. 
The histological evaluation of the pancreatic tissue sections (H\&E-stained) was evaluated in different experimental rat groups (normal control, untreated diabetic, F. cretica L. $250 \mathrm{mg} / \mathrm{kg}$ treated, F. cretica $500 \mathrm{mg} / \mathrm{kg}$ treated, and GB-treated) after 21 days of treatment. Pancreatic tissue images from selected groups are shown in Fig. 6. In normal control rats the pancreatic sections revealed that the islets of Langerhans were abundantly distributed having normal cellular characteristics (moderate to large size, with well-formed, oval to round shape) and diameter of pancreatic islets (Fig. 6a) when compared with other groups.

In contrast, the pancreatic islets of the untreated diabetic rats were less distributed with irregular structure (reduced in size, neither round nor oval), (Fig. 6b). However, in the treated group with $F$. cretica L. extract $(500 \mathrm{mg} / \mathrm{kg})$, a moderate distribution of pancreatic islets was observed, and the islets appeared to have well-formed medium size with oval shape (Fig. 6c), while the treatment with the extract $(250 \mathrm{mg})$ also appeared similar but less in size and number of islet cells (Fig. 6d). The standard drug GB also restored such irregularity to the structure similar to that of the normal control group and improved the islets size (Fig. 6e). The results showed that the extracts were found to improve the pancreatic islets size, but the TM could not bring them to normal as seen in control rats. The administration of the streptozotocin caused a partial structural and dimensional damage to the islets of Langerhans, resulting in necrosis and infiltration of the $\beta$-cells and inhibit insulin secretion causing a state of diabetes in experimental rats. Treatment with positive control drug glibenclamide at the dose of $5 \mathrm{mg} / \mathrm{kg}$ reinstated the normal cellular structure and size of islets. The pancreas histology of the group treated with F. cretica extract $(500 \mathrm{mg} / \mathrm{kg})$ showed an improved architecture of the islets, greater persistence and lesser degree of necrotic changes when compared with that of the untreated diabetic group.

Saleem at al. [31] have reported that extracts of F. Cretica act as DDP-4 inhibitors and suggest that extracts should be investigated for a hypoglycaemic activity in vivo, since the gliptin group of drugs, acting on DDP-4, are effective anti-diabetics. In the present work, we have chemically fingerprinted and demonstrated, for the first time, a hypoglycaemic effect of a TM made from $F$. cretica in normoglycaemic and streptozotocin-treated diabetic rats. Furthermore, we have shown, in this study, that there are additional activities which may augment any DPP-4 inhibitory activity as previously described [31]. We have shown that the extracts composed of phenolic glycosides inhibit $\alpha$-glucosidase activity to the same degree as the anti-diabetic drug acarbose. One of the components fingerprinted in the TM, quercetin-3-O-rutinoside (rutin), has 
been reported to act as an inhibitor of $\alpha$-glycosidase [40] and to decrease plasma glucose levels and increase insulin release in streptozotocin-treated rats [41]. Additionally, rutin increases glucose uptake in hepatocytes in vitro and in mice in vivo, implying its potential role in insulin resistance [42]. Quercetin, the aglycone of rutin, which may be a metabolite of the TM after ingestion, is believed to influence glycemic control in its own right, via reduction of intestinal glucose absorption and, probably, GLP-1 secretion [43].

In addition, routine histological analysis of pancreatic sections confirmed that streptozotocin/nicotinamide treatment caused destruction of pancreatic islet cells. However, a histological examination of pancreatic sections from treatment groups showed that both the extract and Glibenclamide seemed to partially prevent this deterioration. This activity of glibenclamide has been observed in a previous study [44]. The mechanism of this protective effect is not clear; it may be limited to the processes involved in the mutagenic action of streptozotocin and it is not known whether this activity of the extract confers any clinical advantage. However, such a finding might suggest that it could confer additional benefits and should be investigated further. We believe that the current study supports the use of the TM prepared from F. cretica in the treatment of DM in Pakistan. 


\section{References}

1. World Health Organization. Definition and diagnosis of diabetes mellitus and intermediate hyperglycaemia: report of a WHO/IDF consultation. Geneva, Switzerland; 2006

2. Brownlee, M. Biochemistry and Molecular Cell Biology of Diabetic Complications. Nature 2001; 414: 813-820

3. Abdulkareem J, Quwaidhi Al. Epidemiological modelling of type 2 diabetes in Saudi Arabia: predicted trends and public health implications [dissertation]. University of Newcastle; 2013.

4. Hussain M, Naqvi SBS, Khan MA, Rizvi M, Alam S, Abbas A, Akram M. Direct cost of the treatment of diabetes mellitus type 2 in Pakistan. Int J Pharm Pharm Sci 2014; 6: 261-262

5. Garber AJ, Abrahamson MJ, Barzilay JI, Blonde L, Bloomgarden ZT, Bush MA, Dagogo-Jack S, Davidson MB, Einhorn D, Garvey WT, Grunberger G, Handelsman Y, Hirsch IB, Jellinger PS, McGill JB, Mechanick JI, Rosenblit PD, Umpierrez GE, Davidson MH. American association of clinical endocrinologists' comprehensive diabetes management algorithm consensus statement. Endocr Pract 2013; 19: 536-557

6. Rutten G, Verhoeven S, Heine RJ, de Grauw WJC, Cromme PVM, Reenders K, van Ballegooie E, Wiersma TJ. Dutch college of general practitioners' guidelines on type 2 diabetes mellitus. Huisarts Wet 1999; 42: 67-84

7. International Diabetes Federation. Http://www.idf.org/membership/mena/pakistan. Accessed 02 December, 2016

8. Campbell LK, White JR, Campbell PK. Acarbose: its role in the treatment of diabetes mellitus. Ann Pharmacother 1996; 30: 1255-1262

9. Ceriello A. Postprandial hyperglycemia and diabetes complications is it time to treat? Diabetes 2005; 54: $1-7$

10. Kusunoki Y, Katsuno T, Myojin M, Miyakoshi K, Ikawa T, Matsuo T, Ochi F, Tokuda M, Murai K, Miuchi M, Hamaguchi T, Miyagawa J, Namba M. Effect of additional administration of acarbose on blood glucose fluctuations and postprandial hyperglycaemia in patients with type 2 diabetes mellitus under treatment with alogliptin. Endocr J 2013; 60: 431-439

11. Zhou J, Li H, Zhang X, Peng Y, Mo Y, Bao Y, Jia W. Nateglinide and acarbose are comparably effective reducers of postprandial glycemic excursions in Chinese antihyperglycemic agent-naive subjects with type 2 diabetes. Diabetes Technol Ther 2013; 15: $481-488$

12. Kalra S, Gupta Y. The insulin: glucagon ratio and the choice of glucose-lowering drugs. Diabetes Ther 2016; 7: 1-9 
13. Patwardhan B. Traditional medicine: modern approach for affordable healthcare. World Health Organization. WHO Geneva, Switzerland; 2005. Available at http://www.who.int/intellectualproperty/studies/B.Patwardhan2.pdf. Accessed 02 December, 2016.

14. Shaikh BT, Hatcher J. Complementary and alternative medicine in Pakistan: prospects and limitations. Evid Based Complement Alternat Med 2005; 2: 139-142

15. Nazir I, Rahman N, Alvi Z, Hafizur M, Rahman H, Sheridan H. Use of herbal plants to treat diabetes mellitus in Pakistan. An ethnopharmacological survey in the city of Bahawalpur and the Cholistan desert. London BioNat. , University of East London, March 12th Poster presentation 2013.

16. Qureshi H, Asif S, Ahmed H, Al-Kahtani HA, Hayat K. Chemical composition and medicinal significance of Fagonia Cretica: a Review. Nat Prod Res 2016; 30: 625-639

17. Chopra RM, Handa KL, Kapur LD ,Chopra IC. Indigenous Drug of India. 2nd edition. New Delhi, India: Academic Press; 1982: 507

18. Nadkarni KM. Dr. K. M. Nadkarni's Indian materia medica: with Ayurvedic, Unani-tibbi, Siddha, allopathic, homeopathic, naturopathic \& home remedies, appendices \& indexes, Vol. 2. Popular Prakashan; 1954

19 Ahmad M, Khan MA, Arshad M, Zafar M. Ethnophytotherapical approaches for the treatment of diabetes by the local inhabitants of district Attock (Pakistan). Ethnobotanical Leaflets 2004; 1: 7.

20 Ahmad M, Qureshi R, Arshad M, Khan, MA, Zafar M. Traditional herbal remedies used for the treatment of diabetes from the district of Attock (Pakistan). Pak J Bot 2009; 41: 2777-2782

21. Razi MT, Asad MH, Khan T, Chaudhary MZ, Ansari MT, Arshad MA, Saqib QN. Antihaemorrhagic potentials of Fagonia cretica L. against Naja naja karachiensis (black Pakistan cobra) venom. Nat Prod Res 2011; 25: 1902-1907

22. Hussain, A., Zia M, Mirza B. Cytotoxic and antitumor potential of Fagonia cretica L. Turk J Biol 2007; 31: 19-24

23. Rawal AK, Nath DK, Yadav N, Pande S, Meshram SU, Biswas SK. Rubia cordifolia, Fagonia cretica linn and Tinospora cordifolia exert anti-inflammatory properties by modulating platelet aggregation and VEGF, COX-2 and VCAM gene expressions in rat hippocampal slices subjected to ischemic reperfusion injury. Int J Appl Res Nat Prod 2009; 2: 19-26

24. Rawal, AK, Muddeshwar MG, Biswas SK. Rubia cordifolia, Fagonia cretica linn and Tinospora cordifolia exert neuroprotection by modulating the antioxidant system in rat hippocampal slices subjected to oxygen glucose deprivation. BMC Complementary Altern Med $2004 ; 4: 11$ 
25. Sharma K, Zafar R. Occurrence of taraxerol and taraxasterol in medicinal plants. Pharmacogn Rev 2015; 9: 19-23

26. Shishodia S, Majumdar S, Banerjee S, Aggarwal B. Ursolic acid inhibits nuclear factorkappaB activation induced by carcinogenic agents through suppression of IkappaBalpha kinase and p65 phosphorylation: correlation with down-regulation of cyclooxygenase 2, matrix metalloproteinase 9, and cyclin D1. Cancer Res 2003; 63: 4375-4383

27. Abdel KSM, Miyase T, El-Ashaal HA, Meleek FR. Triterpenoid saponins from Fagonia cretica. Phytochemistry 2000; 54: 853-859

28. Anjum MI, Ahmed E, Jabbar A, Malik A, Ashraf M, Moazzam M, Rasool MA. Antimicrobial Constituents from Fagonia cretica. Jour Chem Soc Pak 2007; 29: 634-639

29. El- Negoumy SI, Al-Wakeel SAM, El- Hadidi MN, Saleh NAM. The flavonoids of the Fagonia arabica-complex (Zygophyllaceae). Phytochemistry 1986; 25: 2423-2424

30. Lam M, Carmichael AR, Griffiths HR. An aqueous extract of Fagonia cretica induces DNA damage, cell cycle arrest and apoptosis in breast cancer cells via FOXO3a and p53 expression. PLoS One 2012; 7: e40152

31. Saleem S, Jafri L, ul Haq I, Chang LC, Calderwood D, Green BD, Mirza B. Plants Fagonia cretica L. and Hedera nepalensis K. Koch contain natural compounds with potent dipeptidyl peptidase-4 (DPP-4) inhibitory activity. J Ethnopharmacol 2014; 156: 26-32.

32. Sheridan H, Krenn L, Jiang R, Sutherland I, Ignatova S, Marmann A, Liang XM, Sendker J. The potential of metabolic fingerprinting as a tool for the modernisation of TCM preparations. J Ethnopharmacol 2012; 140: 482-491

33. Sheridan H, Kopp B, Krenn L, Guo D, Sendker J.Traditional Chinese herbal medicine preparation: invoking the butterfly effect. Science 2015; 350: S64-S66

34. Sendker J, Ellendorff T, Hölzenbein A. Occurrence of benzoic acid esters as putative catabolites of prunasin in senescent leaves of Prunus laurocerasus. J Nat Prod 2016; 79: 17241729

35. Shaker KH, Bernhardt M, Elgamal MHA, Seifert K. Sulfonated triterpenoid saponins from Fagonia indica. Z Naturforsch 2000; 55c: 520-523

36. Pham-Huy LA, He H, Pham-Huy C. Free radicals, antioxidants in disease and health. Int J Biomed Sci 2008; 4: 89-96

37. Wongsa $\mathrm{P}$, Chaiwarit J, Zamaludien A. In vitro screening of phenolic compounds, potential inhibition against $\alpha$-amylase and $\alpha$-glucosidase of culinary herbs in Thailand. Food Chem 2012; 131: 964-971

38. Kalra, S. Alpha glucosidase inhibitors. J Pak Med Assoc 2014; 64: 474-476 
39. Ma HY, Gao HY, Sun L, Huang J, Xu XM, Wu LJ. Constituents with $\alpha$-glucosidase and advanced glycation end-product formation inhibitory activities from Salvia miltiorrhiza Bge. J Nat Med 2011; 65: 37-42

40. Jo SH, Ka EH, Lee HS, Apostolidis HD, Jang HD, Kwon YI. Comparison of antioxidant potential and rat intestinal $\alpha$-glucosidases inhibitory activities of quercetin, rutin, and isoquercetin. Int J Appl Res Nat Prod 2009; 2: 52-60.

41. Kamalakkannan N, Prince PSM. Antihypercaemic and antioxidant effect of rutin, a polyphenolic flavonoid, in streptozotocin-induced diabetic wistar rats. Basic Clin Pharmacol Toxicol 2006; 98: 97-103

42. Lee CC, Hsu WH, Shen SR, Cheng YH, Wu SC. Fagopyrum tataricum (buckwheat) improved high-glucose-induced insulin resistance in mouse hepatocytes and diabetes in fructoserich diet-induced mice. Exp Diabetes Res 2012; 2012: 375673

43. Chang CLT, Lin Y, Bartolome AP, Chen YC, Chiu SC, Yang WC. Herbal therapies for type 2 diabetes mellitus: chemistry, biology, and potential application of selected plants and compounds. Evid Based Complement Alternat Med 2013; 2013:378657

40. Rabbani SI, Devi K, Khanam S. Protective role of glibenclamide against nicotinamidestreptozotocin induced nuclear damage in diabetic Wistar rats. J Pharmacol Pharmacother 2010; 1: $18-23$ 